Original Research

\title{
Experimental and Statistical Evaluation of the Interaction Effect of Recycled Aggregate and Water/Cement Ratio on Concrete Compressive Strength
}

\author{
Mônica Batista Leite, Paulo Roberto Lopes Lima *
}

PPGECEA/UEFS, Av. Transnordestina, SN, Novo Horizonte, Feira de Santana, Bahia, Brazil; E-Mails: lima.prl@pq.cnpq.br; mleite.uefs@gmail.com

* Correspondence: Paulo Roberto Lopes Lima; E-Mail: lima.prl@pq.cnpq.br

Academic Editor: Jorge de Brito

Special Issue: Wastes, Residues and Byproducts for the Production of Construction Materials

Recent Progress in Materials

2021, volume 3 , issue 3

doi:10.21926/rpm.2103032
Received: March 07, 2021

Accepted: July 02, 2021

Published: July 28, 2021

\begin{abstract}
The production of concrete using recycled aggregates, obtained from the processing of construction and demolition waste, is extensively practiced worldwide. However, the effect of simultaneous adding fine recycled aggregate and the recycled coarse aggregate on the mechanical properties of concrete is still unfamiliar. This work aims to evaluate the influence of the water/cement ratio (WC Ratio), the fine recycled aggregate content (\%FRA), the coarse recycled aggregate content (\%CRA), as well as the interaction between factors on the compressive strength of concrete. Accordingly, a factorial design experiment was developed, analyzing these factors at three levels, which resulted in the production of 27 mixtures. These levels were: WC Ratio (0.50; 0.65 and 0.80); \%FRA (0; 50 and 100) and \%CRA (0; 50 and 100). Statistical analysis was performed on the response surface, and an enhanced approximation of the two-way interaction model was identified. The results indicate that the substitution of the natural aggregate with recycled aggregate shows a significant influence on the compressive strength, and its effect depends on the water-cement ratio. Furthermore, considering the interaction between the content and type of aggregate and
\end{abstract}

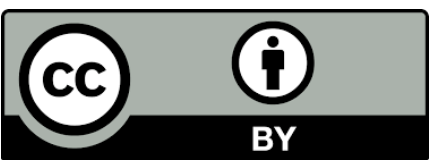

(C) 2021 by the author. This is an open access article distributed under the conditions of the Creative Commons by Attribution License, which permits unrestricted use, distribution, and reproduction in any medium or format, provided the original work is correctly cited. 
the water-cement ratio is fundamental for obtaining the proper mix design of this type of concrete.

\section{Keywords}

Construction and demolition waste; compressive strength; recycled aggregate; statistical analysis; design of experiment

\section{Introduction}

The construction industry belongs to one of the most important sectors of the world economy for its potential to create jobs (direct and indirect) and due to its beneficial effects on the balance of trade and the level of inflation. However, this sector makes a significant impact on the environment considering the high consumption of mineral resources and energy and the large volumes of waste generated during the construction and demolition process. Aggregates utilized in the construction industry are the most consumed mineral inputs in the world. The aggregates used for civil construction represented $66 \%$ of the consumption of mineral goods in the year 2010 in the United States; in Europe, 3.25 billion tons of aggregates were produced in 2008, while in China, approximately 4 billion tons are consumed yearly [1]. Therefore, there is an enormous impact on the environment, as aggregate mining operations could cause changes in the physical parameters of the river current, including channel geometry, bed elevation, substrate composition, and stability [2].

The utilization of the waste generated in the construction industry for the production of aggregates possess some advantages regarding other residues: the grains generally have the same nature as the new material (concrete or mortar); there is an availability of large volume [3, 4]; and, as it is generated within the city, it reduces the need for transportation which in turn reduces the energy consumption and $\mathrm{CO}_{2}$ emissions.

The use of aggregates from construction and demolition wastes (CDW) is standardized in several countries, and its applicability has been extended to asphalt concrete mortar and even concrete structures [3, 5-7]. However, some technical barriers, such as an increased shrinkage and creep in concrete and mortar and a reduced elasticity module, limit the substitution of the natural aggregate by the recycled one [8-10]. Another important factor is the heterogeneity of the properties of recycled aggregate, which is a result of the composition, shape, and texture of the grains that are also a function of the origin of waste and the type of crusher used, etc. Consequently, there is a wide variation seen in the physical and mechanical properties of concrete having recycled aggregate obtained from the CDW. Due to this, most studies based on the application of recycled aggregates have been dedicated to aggregates formed by recycled concrete, including the portion corresponding to the coarse aggregate, whose characteristics are less variable. These results, on the other hand, are a limitation to the use of construction and demolition wastes that consist of ceramic and mortar waste, in addition to concrete waste.

The simultaneous substitution of natural aggregates, fine and coarse, by recycled aggregates affects the properties of concrete differently. This is because, in addition to the individual influence of each aggregate, the interaction between them affects the mechanical behavior [11]. It 
is understood that the effect of interaction between the fine and coarse aggregate on the mechanical properties provides an adequate mix design for the concretes and allows the reduction of the variability of their behavior. Similarly, it is important to understand the interaction between the recycled aggregate and the water-cement ratio, as several studies indicate that the effect on the strength of the recycled aggregate varies according to the watercement ratio of the concrete. The evaluation of a large amount of data requires the use of appropriate mathematical tools for assessing the interaction between the material properties. For this, some studies employed neural networks, experiment design, or factorial design procedures [12-14].

The objective of this work is to evaluate the influence of the fine aggregate content (\%FRA), coarse aggregate (\%CRA), and the water-cement ratio (WC Ratio), as well as the effect of the interaction between these factors on the compressive strength of concrete. For this, statistical modeling was carried out using a $3^{3}$ factorial design, indicating that there would be three factors (WC Ratio, \%FRA and \%CRA) varying at three levels each. The calibration of the model was carried out with the production of 27 different concretes. From the mathematical function obtained, it was possible to trace response surfaces for the compressive strength analysis of the concretes.

\section{Materials and Methods}

\subsection{Materials}

High initial strength cement (ASTM Type III) was used in producing all the mixtures. The fine natural aggregate (FNA) used was formed by combining a commercially available fine sand (FNA1) and a medium sand (FNA2). The coarse natural aggregate (CNA) consisted of gravel having a granitic origin. Table 1 provides the results of the characterization test of natural aggregates.

Table 1 Aggregate Properties.

\begin{tabular}{llllll}
\hline Property & FNA1 & FNA2 & FRA & CNA & CRA \\
\hline Maximum size aggregate $(\mathrm{mm})$ & 1.20 & 2.40 & 4.80 & 9.50 & 12.50 \\
Fineness & 1.68 & 2.9 & 2.56 & 5.43 & 6.23 \\
Specific gravity $\left(\mathrm{kg} / \mathrm{dm}^{3}\right)$ & 2.59 & 2.55 & 2.51 & 2.73 & 2.41 \\
Bulk density $\left(\mathrm{kg} / \mathrm{dm}^{3}\right)$ & 1.53 & 1.39 & 1.27 & 1.38 & 0.99 \\
Water absorption rate (\%) & 0.10 & 0.20 & 21.00 & 0.50 & 11.3 \\
Fines content (\%) & 1.70 & 0.70 & 10.40 & 1.20 & 0.70 \\
Los Angeles abrasion value (\%) & - & - & - & 19.70 & 63.70 \\
\hline
\end{tabular}

For the production of the recycled aggregate, 12 tons of construction and demolition waste (CDW) samples were collected, which was predominantly composed of concrete, mortar, and ceramic material residues, as shown in Figure 1. The recycled aggregate was manufactured by grinding the CDW in a jaw crusher and mechanical sieving, after which the waste was classified and split into coarse and fine aggregate. Table 1 shows the characterization test results of the fine recycled aggregate (FRA) and coarse recycled aggregate (CRA). Figure 2 shows the granulometric curves of aggregates. 


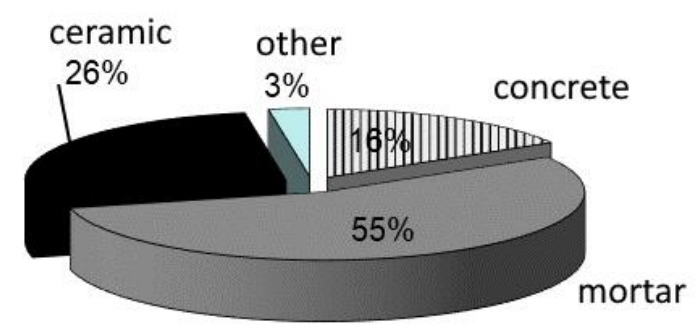

Figure 1 Composition of CDW.

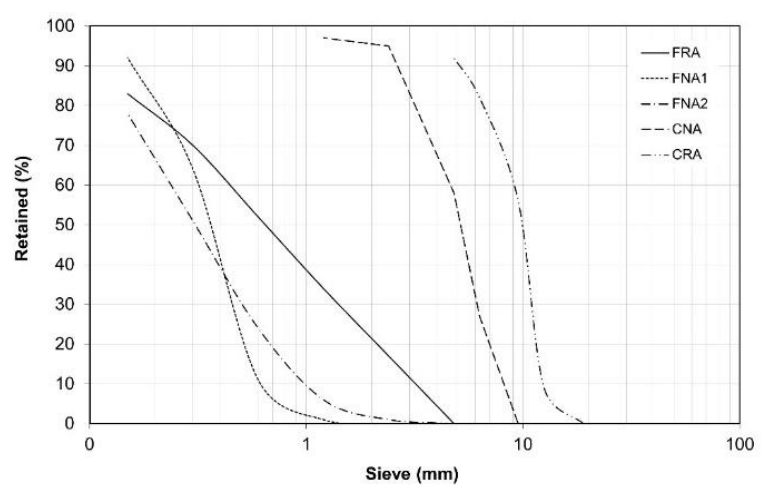

Figure 2 Particle size curve of aggregates.

\subsection{Experiment Design}

A complete factorial design was defined for determining the influence of the recycled aggregate content and the water-cement ratio on the compressive strength of concrete. In Figure 3, a factorial plan $3^{3}$ was defined, consisting of 3 factors (\%FRA, \%RCA and WC Ratio) and three levels (low, high, and intermediate):

- Factor 1: WC Ratio, with levels of $0.50,0.65$, and 0.80;

- Factor 2: \% FRA, with levels 0, 50\% and 100\%;

- Factor 3: \% RCA, with levels 0, 50\% and 100\%.

It is possible to determine the significance of the existing parameters from the statistical analysis made from the experiment, through the analysis of variance, and to trace a response surface that allows evaluating the effect of interaction between several dependent variables (\%FRA, \%RCA, WC Ratio) on the compressive strength.

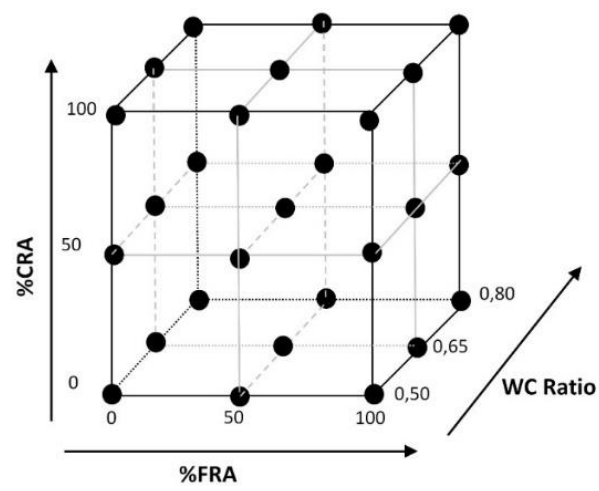

Figure 3 Geometric representation of the factorial design. 
The ANOVA variance analysis was chosen for testing the effect of the factors on the interest responses, with three replications being performed to calculate the quadratic sum of the error. These replications were also important in minimizing the experimental error. STATISTICA ${ }^{\circledR}$ software was used for analyzing the results.

\subsection{Mix Design and Production Method}

The 27 mixtures produced, based on the presented experiment project, are shown in Tables 2, 3, and 4. It was observed in Table 1 that the water absorption rates of fine and coarse recycled aggregates were greater than the natural aggregates, and nearly half of the total water was absorbed in the first $10 \mathrm{~min}$. To avoid the loss of workability of concretes with the recycled aggregate, the water absorption of the recycled aggregate was partially compensated, as suggested in [15].

Table 2 Mix proportion, $\mathrm{kg} / \mathrm{m}^{3}$, of concrete $(\mathrm{WC}$ ratio $=0.50)$.

\begin{tabular}{lllllllllll}
\hline Mixtures & C & FNA1 & FNA2 & FRA & CNA & CRA & W & CW & TW & $\begin{array}{l}\text { Slump } \\
\text { (mm) }\end{array}$ \\
\hline REF & 455 & 503 & 335 & 0 & 793 & 0 & 228 & 0 & 228 & 130 \\
$\mathbf{5 0 \% ~ F R A ~}$ & 455 & 251 & 168 & 401 & 793 & 0 & 228 & 34 & 261 & 80 \\
$\mathbf{1 0 0 \% ~ F R A ~}$ & 455 & - & - & 802 & 793 & 0 & 228 & 67 & 295 & 65 \\
$\mathbf{5 0 \% ~ C R A ~}$ & 455 & 503 & 335 & 0 & 396 & 366 & 228 & 15 & 242 & 65 \\
$\mathbf{1 0 0 \%}$ CRA & 455 & 503 & 335 & 0 & - & 732 & 228 & 29 & 257 & 45 \\
$\mathbf{5 0 - 5 0 \% ~ C R A / F R A ~}$ & 455 & 251 & 168 & 401 & 396 & 366 & 228 & 48 & 276 & 50 \\
$\mathbf{1 0 0 - 1 0 0 \% ~ C R A / F R A ~}$ & 455 & - & - & 802 & - & 732 & 228 & 97 & 324 & 15 \\
$\mathbf{5 0 - 1 0 0 \% ~ C R A / F R A ~}$ & 455 & - & - & 802 & 396 & 366 & 228 & 82 & 310 & 35 \\
$\mathbf{1 0 0 - 5 0 \% ~ C R A / F R A ~}$ & 455 & 251 & 168 & 401 & - & 732 & 228 & 63 & 291 & 10 \\
\hline
\end{tabular}

$\mathrm{C}=$ cement; FNA = fine natural aggregate; FRA = fine recycled aggregate; CNA = coarse natural aggregate; $C R A=$ coarse recycled aggregate; $W=$ water; $C W=$ compensation water; $T W=$ total water

Table 3 Mix proportion, $\mathrm{kg} / \mathrm{m}^{3}$, and slump of concrete (WC ratio $\left.=0.65\right)$.

\begin{tabular}{lllllllllll}
\hline Mixtures & C & FNA1 & FNA2 & FRA & CNA & CRA & W & CW & TW & $\begin{array}{l}\text { Slump } \\
\text { (mm) }\end{array}$ \\
\hline REF & 362 & 545 & 364 & 0 & 779 & 0 & 235 & 0 & 235 & 190 \\
$\mathbf{5 0 \% ~ F R A ~}$ & 362 & 273 & 182 & 435 & 779 & 0 & 235 & 37 & 272 & 160 \\
$\mathbf{1 0 0 \% ~ F R A ~}$ & 362 & - & - & 870 & 779 & 0 & 235 & 73 & 309 & 75 \\
$\mathbf{5 0 \% ~ C R A ~}$ & 362 & 545 & 364 & 0 & 389 & 360 & 235 & 14 & 250 & 160 \\
$\mathbf{1 0 0 \%}$ CRA & 362 & 545 & 364 & 0 & - & 720 & 235 & 29 & 264 & 75 \\
$\mathbf{5 0 - 5 0 \%}$ CRA/FRA & 362 & 273 & 182 & 435 & 389 & 360 & 235 & 51 & 286 & 150 \\
$\mathbf{1 0 0 - 1 0 0 \% ~ C R A / F R A ~}$ & 362 & - & - & 870 & - & 720 & 235 & 102 & 337 & 70 \\
$\mathbf{5 0 - 1 0 0 \% ~ C R A / F R A ~}$ & 362 & - & - & 870 & 389 & 360 & 235 & 87 & 323 & 75 \\
$\mathbf{1 0 0 - 5 0 \% ~ C R A / F R A ~}$ & 362 & 273 & 182 & 435 & - & 720 & 235 & 65 & 301 & 135 \\
\hline
\end{tabular}


Table 4 Mix proportion, $\mathrm{kg} / \mathrm{m}^{3}$, of concrete $(\mathrm{WC}$ ratio $=0.80)$.

\begin{tabular}{lllllllllll}
\hline Mixtures & C & FNA1 & FNA2 & FRA & CNA & CRA & W & CW & TW & $\begin{array}{l}\text { Slump } \\
\text { (mm) }\end{array}$ \\
\hline REF & 300 & 574 & 383 & 0 & 770 & 0 & 240 & 0 & 240 & 175 \\
$\mathbf{5 0 \% ~ F R A ~}$ & 300 & 287 & 191 & 458 & 770 & 0 & 240 & 38 & 279 & 155 \\
$\mathbf{1 0 0 \% ~ F R A ~}$ & 300 & - & - & 916 & 770 & 0 & 240 & 77 & 317 & 80 \\
$\mathbf{5 0 \% ~ C R A ~}$ & 300 & 574 & 383 & 0 & 385 & 356 & 240 & 14 & 254 & 115 \\
$\mathbf{1 0 0 \%}$ CRA & 300 & 574 & 383 & 0 & - & 712 & 240 & 28 & 269 & 85 \\
$\mathbf{5 0 - 5 0 \% ~ C R A / F R A ~}$ & 300 & 287 & 191 & 458 & 385 & 356 & 240 & 53 & 293 & 115 \\
$\mathbf{1 0 0 - 1 0 0 \% ~ C R A / F R A ~}$ & 300 & - & - & 916 & - & 712 & 240 & 105 & 346 & 50 \\
$\mathbf{5 0 - 1 0 0 \% ~ C R A / F R A ~}$ & 300 & - & - & 916 & 385 & 356 & 240 & 91 & 331 & 80 \\
$\mathbf{1 0 0 - 5 0 \% ~ C R A / F R A ~}$ & 300 & 287 & 191 & 458 & - & 712 & 240 & 67 & 307 & $\mathbf{7 5}$ \\
\hline
\end{tabular}

The amount of water referred to as compensation (CW) was added along with the mixing water of each concrete mixture.

The concrete mixer, which produced the concretes, consisted of an inclined axis and a capacity of 320 liters. The following sequence was followed for the execution of the mixtures: $100 \%$ of the coarse aggregate, $50 \%$ of water, $100 \%$ of the cement; $25 \%$ of water; $100 \%$ of the fine aggregate; and the remaining water. The mixing was carried out for $8 \mathrm{~min}$ before laying the cement to guarantee its perfect homogenization, especially because the recycled aggregate was implemented.

\subsection{Test Method}

Three cylindrical specimens (diameter $10 \mathrm{~cm}$ and height $20 \mathrm{~cm}$ ) were molded for each mixture, in a total of 81 samples that were compacted using a vibrating table. The samples were air-cured in the first $24 \mathrm{~h}$ and were later kept in a humid laboratory chamber, which maintained a temperature of $23 \pm 2{ }^{\circ} \mathrm{C}$ and relative humidity greater than $95 \%$ and were remained there until a period of 28 days. The test for axial compression strength was performed on a $200 \mathrm{t}$ hydraulic machine, as per NBR 5739/2007 [16].

\section{Results and Discussion}

\subsection{Experimental Results}

The experimental results for the concrete compressive strength test are shown in Figure 4. A general tendency in the reduction of compressive strength is observed when there is an increase in the content of recycled aggregate, confirming what has already been observed by several authors $[8,17]$. However, it can also be seen in Figure 4 that the intensity of reduction is affected by the type of aggregate present in the mixture and by the water-cement ratio. 

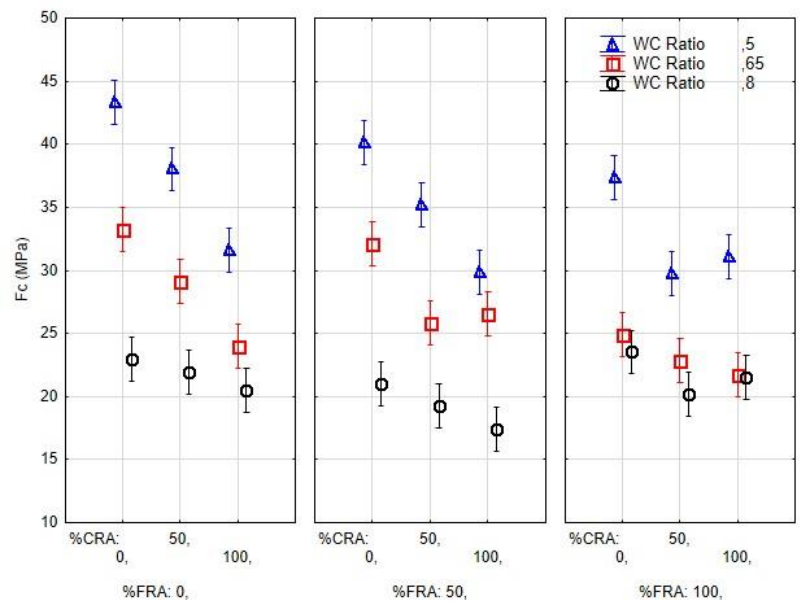

Figure 4 Experimental results of compressive strength.

For mixtures containing only coarse recycled aggregate, i.e., when the FRA $=0 \%$, a reduction is seen in the compressive strength with an increase in the CRA content. However, the intensity of reduction depends on the WC Ratio, as shown in Figure 5. For the concrete having a WC Ratio equal to 0.50 or 0.65 , the maximum reduction in mechanical strength is about $17 \%$. On the other hand, for the concrete having a WC Ratio equal to 0.8 , the reduction seen is $11 \%$.

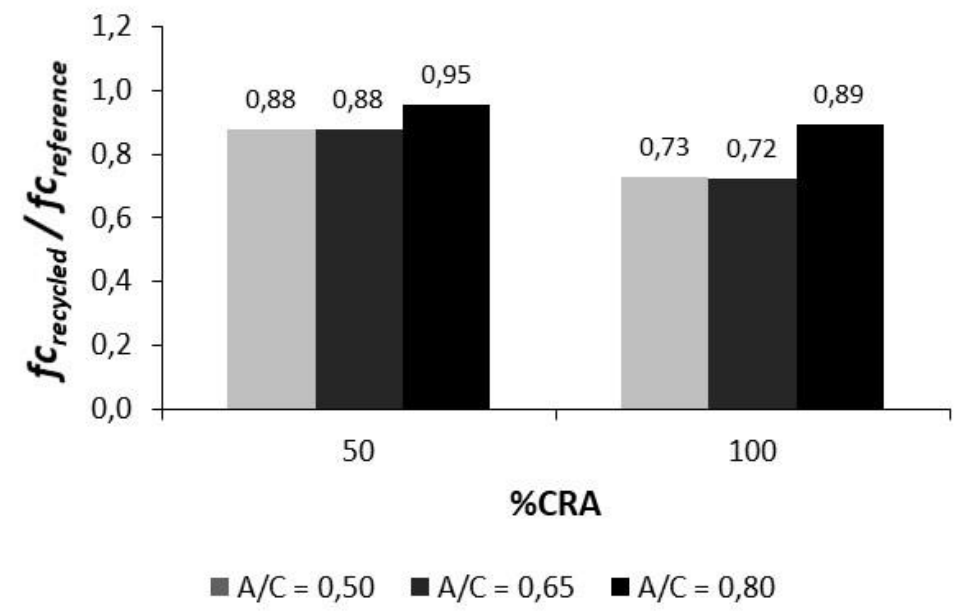

Figure 5 Influence of WC Ratio and\% CRA on the compressive strength.

The effect of the WC Ratio on the compressive strength of recycled concrete is associated with the mode of breaking. The Concrete having a smaller WC Ratio presents a paste with greater mechanical strength, and the rupture of the same primarily occurs due to the rupture of the aggregate grain, which becomes the fragile link in the system. This phenomenon is like the failure mode observed in high-performance concrete or lightweight concrete. Thus, the addition of recycled aggregate, which has a lower mechanical strength compared to the natural aggregate, changes the compressive strength of the concrete. The Los Angeles Abrasion values, which are presented in Table 1, indicate a mass loss of $19.7 \%$ for the natural aggregate and $63 \%$ for the recycled aggregate, which demonstrates its greatest fragility.

From Figure 6, the rupture surface assessment of the concrete with recycled aggregate indicates the rupture of the concrete, ceramic, and mortar grains originated from the CDW. 
Besides these, other factors also contribute to the rupture of the recycled coarse aggregate, such as the densification of the transition zone and stronger adherence between the cement paste and the aggregate [11]. The surface of the recycled aggregates is rougher and also more porous compared to the natural aggregate due to the presence of adhered old mortar, which contributes to the interpenetration of the cement paste [18].

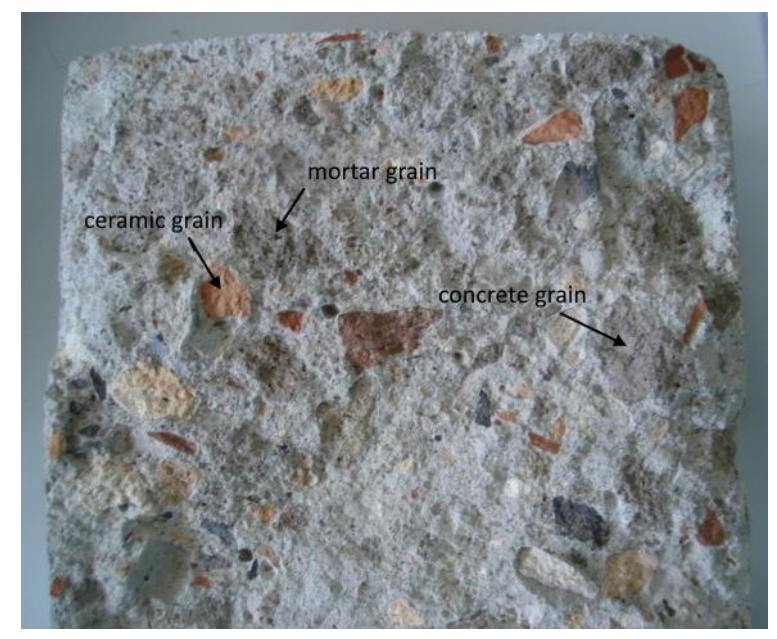

Figure 6 Fractured surfaces of concrete along with the recycled aggregate.

Figure 7 shows the effect of fine recycled aggregate on the compressive strength of concrete.

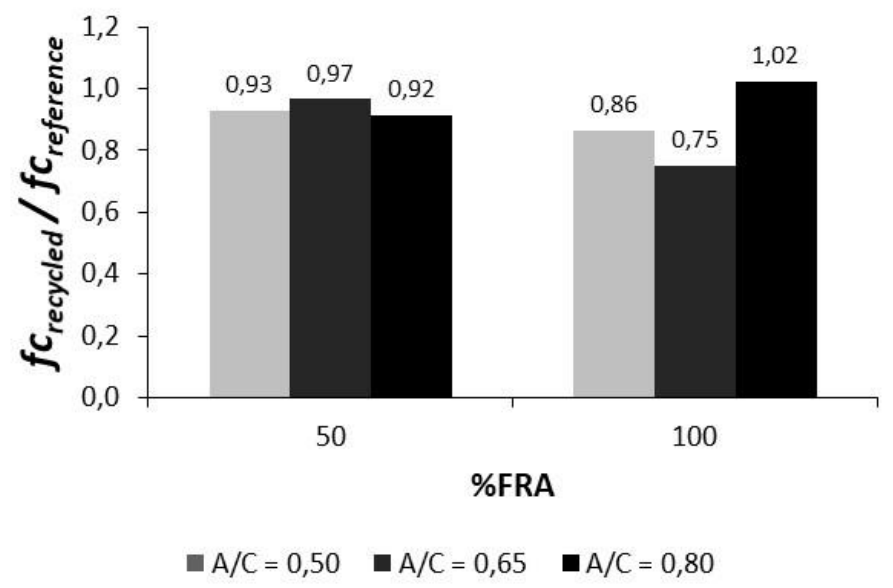

Figure 7 Influence of WC Ratio and\% FRA on the compressive strength.

The effect on the strength by the \%FRA did not show the same downward trend when as seen during the addition of the CRA. It was seen that concrete with fine recycled aggregate was the most affected by the WC Ratio. The substitution of the fine natural aggregate by the recycled one resulted in a reduction in the compressive strength by up to $25 \%$ of the WC Ratio, which was equal to 0.65 , but in an increase in compressive strength for concrete having a WC Ratio of 0.80 .

The influence of fine aggregates on the mechanical behavior of concrete is determined by factors such as surface texture and granulometry. The fine recycled aggregates produced in this work possessed a much rougher and irregular surface compared to the natural fine aggregate, as shown in Figures 8 a and 8 b, respectively. The excessive presence of fines (10.4\%) in the recycled 
aggregate resulted in a reduction in workability, which affected the density of the concrete and in turn, its porosity and mechanical strength. In addition, this fine material is deposited on the granular surface of the recycled fine aggregate, as shown in Figure $8 \mathrm{c}$. This affected the adhesion between the cement paste, resulting in a loss of mechanical strength. On the other hand, the presence of ceramic fines and anhydrous cement resulted in an increase in the strength of the concrete due to the pozzolanic effect, as observed by [13].
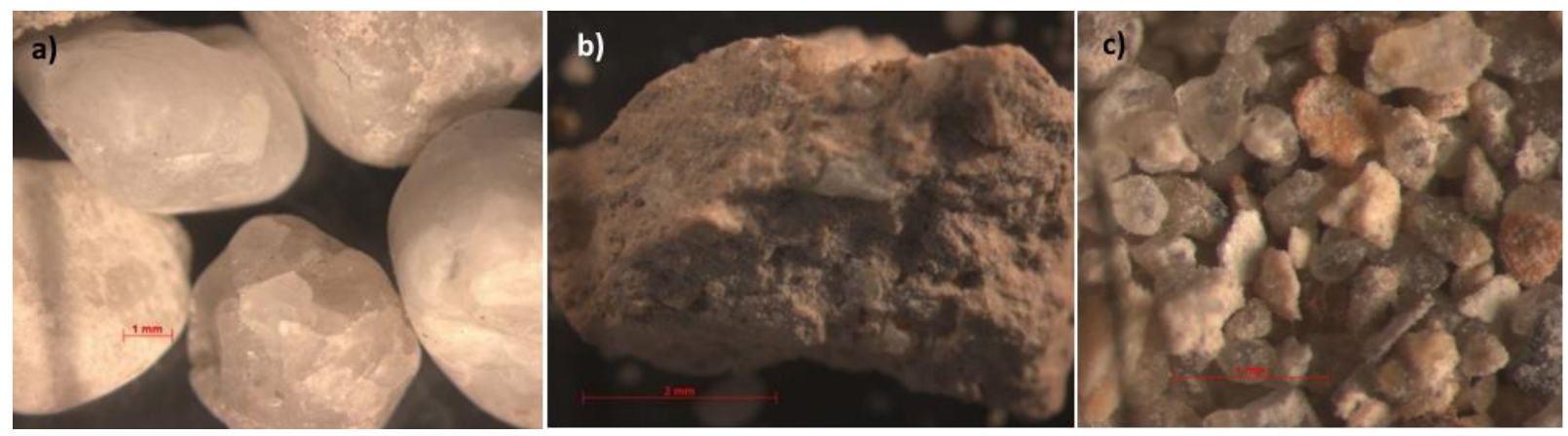

Figure 8 Morphology of aggregates: a) natural grain; b) recycled grain; c) presence of surface powder.

\subsection{Statistical Analysis}

\subsubsection{Multiple Regression Model}

Based on the statistical analysis of the experiment, it is possible to determine the significance of the existing parameters and formulate a function that could estimate any value of mechanical strength $\left(f_{c}\right)$ for any of the water-cement ratio values $\left(x_{1}\right)$, fine recycled aggregate $\left(x_{2}\right)$ or coarse recycled aggregate $\left(x_{3}\right)$, within the parameters of the experiment. As the objective of this work was to evaluate the iteration between the given factors, it is possible to use a complete multiple regression model given by:

$$
\begin{gathered}
f_{c}=\beta_{0}+\beta_{1} x_{1}+\beta_{2} x_{1}^{2}+\beta_{3} x_{2}+\beta_{4} x_{2}^{2}+\beta_{5} x_{3}+\beta_{6} x_{3}^{2}+\beta_{7} x_{1} x_{2}+ \\
\beta_{8} x_{1} x_{2}^{2}+\beta_{9} x_{1}^{2} x_{2}+\beta_{10} x_{1}^{2} x_{2}^{2}+\beta_{11} x_{1} x_{3}+\beta_{12} x_{1} x_{3}^{2}+\beta_{13} x_{1}^{2} x_{3}+ \\
\beta_{14} x_{1}^{2} x_{3}^{2}+\beta_{15} x_{2} x_{3}+\beta_{16} x_{2} x_{3}^{2}+\beta_{17} x_{2}^{2} x_{3}+\beta_{18} x_{2}^{2} x_{3}^{2}+\varepsilon
\end{gathered}
$$

where $f_{c}$ represents the dependent variable (or response variable), $x_{1}, x_{2}$, and $x_{3}$ being the independent variables (factors), while $b_{i}$ and $b_{i j}$ are the parameters that measure the effects of the factors, including the interaction between them, respectively, and where $\varepsilon$ is the random error that follows the normal distribution.

The $b$ coefficients are obtained through a regression analysis of the experimental results by using the least-squares method. The mathematical equation obtained is used for determining the response surface that analyzes the interaction between the independent variables and could be performed in three main ways, considering the non-existence of the interaction, the interaction between the linear terms (linear two-way), or considering the interaction between the non-linear terms (two-way quadratic). The coefficients obtained, as well as the determination coefficient when compared to equation (1) with the experimental results, are shown in Table 5. 
Table 5 Coefficients obtained for the mathematical model.

\begin{tabular}{|c|c|c|c|c|}
\hline Variable/interaction & Coefficient & $\begin{array}{l}\text { Number of } \\
\text { interactions }\end{array}$ & $\begin{array}{l}\text { 2-way interactions } \\
\text { (linear - linear) }\end{array}$ & $\begin{array}{l}\text { 2-way interactions } \\
\text { (linear - quadratic) }\end{array}$ \\
\hline Average & $b_{0}$ & 87,696 & 101,242 & 91,160 \\
\hline (1) CW Ratio (L) & $b_{1}$ & $-124,255$ & $-143,570$ & $-115,572$ \\
\hline CW Ratio (Q) & $b_{2}$ & 59,095 & 59,095 & 39,177 \\
\hline (2)\%FRA(L) & $b_{3}$ & $-0,042$ & $-0,167$ & $-1,923$ \\
\hline \%FRA(Q) & $\mathbf{b}_{4}$ & 0,000 & 0,000 & 0,023 \\
\hline (3)\%CRA(L) & $b_{5}$ & $-0,102$ & $-0,267$ & $-0,121$ \\
\hline \%CRA(Q) & $b_{6}$ & 0,000 & 0,000 & $-0,001$ \\
\hline $1 \mathrm{~L}$ by $2 \mathrm{~L}$ & $b_{7}$ & & 0,162 & 6,187 \\
\hline $1 L$ by $2 Q$ & $b_{8}$ & & 0,224 & $-0,079$ \\
\hline $1 Q$ by $2 L$ & $b_{9}$ & & 0,000 & $-4,881$ \\
\hline $1 Q$ by $2 Q$ & $b_{10}$ & & & 0,063 \\
\hline $1 \mathrm{~L}$ by $3 \mathrm{~L}$ & $b_{11}$ & & & $-0,125$ \\
\hline $1 L$ by $3 Q$ & $b_{12}$ & & & 0,004 \\
\hline $1 Q$ by $3 L$ & $\mathbf{b}_{13}$ & & & 0,321 \\
\hline 1Q by $3 Q$ & $\mathbf{b}_{14}$ & & & $-0,003$ \\
\hline $2 \mathrm{~L}$ by $3 \mathrm{~L}$ & $\mathbf{b}_{15}$ & & & $-0,001$ \\
\hline $2 L$ by $3 Q$ & $b_{16}$ & & & 0,000 \\
\hline $2 Q$ by $3 L$ & $\mathbf{b}_{17}$ & & & 0,000 \\
\hline $2 Q$ by $3 Q$ & $b_{18}$ & & & $-0,000$ \\
\hline $\mathbf{R}^{2}$ & & 0,88 & 0.93 & 0.96 \\
\hline MS Residual & & 6.16 & 3.74 & 2.28 \\
\hline
\end{tabular}

Figure 9 shows the best agreement between the observed results and the predicted values obtained by the 2-way interaction ( $\mathrm{L}-\mathrm{Q}$ ) model, which presented an $\mathrm{R}^{2}=0.96$. Due to this, the latter model was used for establishing the response surface and analysis of the effect of each factor and the interaction between them on the compressive strength of the concretes.
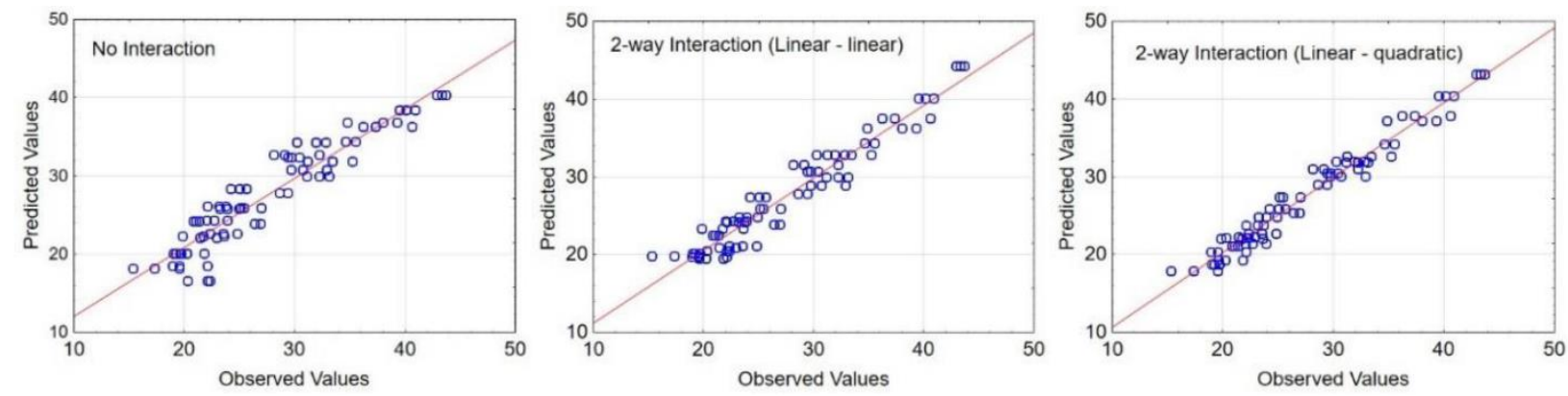

Figure 9 Effect of the analysis model on the theoretical prediction of experimentally observed values.

Analysis of variance (ANOVA) was conducted for assessing the significance of each factor and the respective interaction between them, up to a confidence level of $95 \%$. In Table 6 , the results 
presented indicate that the CW Ratio (Linear) and the \%CRA (Linear) are taken to be the main parameters (have the highest SS value) followed by the \%FRA (Linear), confirming the influence of these parameters for the compressive strength of the concretes. The interaction between the factors is also shown to be significantly relevant, demonstrating the importance of this condition in the concrete mix design.

Table 6 ANOVA for compressive strength model (Confidence level: 95\%).

\begin{tabular}{|c|c|c|c|c|c|c|}
\hline Variable/interaction & SS & df & MS & $\mathbf{F}$ & $\mathbf{p}$ & Significance \\
\hline (1)CW Ratio (L) & 2733,512 & 1 & 2733,512 & 1195,992 & 0,000000 & Yes \\
\hline CW Ratio (Q) & 31,822 & 1 & 31,822 & 13,923 & 0,000415 & Yes \\
\hline (2)\%FRA(L) & 167,834 & 1 & 167,834 & 73,432 & 0,000000 & Yes \\
\hline \%FRA(Q) & 0,478 & 1 & 0,478 & 0,209 & 0,649033 & No \\
\hline (3)\%CRA(L) & 493,227 & 1 & 493,227 & 215,801 & 0,000000 & Yes \\
\hline \%CRA(Q) & 19,082 & 1 & 19,082 & 8,349 & 0,005310 & Yes \\
\hline $1 \mathrm{~L}$ by $2 \mathrm{~L}$ & 53,047 & 1 & 53,047 & 23,210 & 0,000010 & Yes \\
\hline $1 L$ by $2 Q$ & 17,360 & 1 & 17,360 & 7,596 & 0,007674 & Yes \\
\hline $1 Q$ by $2 L$ & 29,978 & 1 & 29,978 & 13,116 & 0,000591 & Yes \\
\hline $1 Q$ by $2 Q$ & 50,016 & 1 & 50,016 & 21,884 & 0,000016 & Yes \\
\hline $1 L$ by $3 L$ & 102,010 & 1 & 102,010 & 44,632 & 0,000000 & Yes \\
\hline $1 L$ by $3 Q$ & 0,784 & 1 & 0,784 & 0,343 & 0,560289 & No \\
\hline $1 Q$ by $3 L$ & 0,003 & 1 & 0,003 & 0,001 & 0,969659 & No \\
\hline $1 Q$ by $3 Q$ & 0,143 & 1 & 0,143 & 0,062 & 0,803502 & No \\
\hline $2 L$ by $3 L$ & 35,403 & 1 & 35,403 & 15,490 & 0,000212 & Yes \\
\hline $2 L$ by $3 Q$ & 23,989 & 1 & 23,989 & 10,496 & 0,001925 & Yes \\
\hline $2 Q$ by $3 L$ & 1,541 & 1 & 1,541 & 0,674 & 0,414751 & No \\
\hline $2 Q$ by $3 Q$ & 0,016 & 1 & 0,016 & 0,007 & 0,932915 & No \\
\hline Error & 141,705 & 62 & 2,286 & & & \\
\hline Total SS & 3901,950 & 80 & & & & \\
\hline
\end{tabular}

$\mathrm{SS}=$ square sum; $\mathrm{df}=$ degree of freedom; $\mathrm{MS}=$ mean square

Considering the significance of the factors presented in Table 6, Equation (1) can be simplified as follows:

$$
\begin{aligned}
f_{c}= & \beta_{0}+\beta_{1} x_{1}+\beta_{2} x_{1}^{2}+\beta_{3} x_{2}+\beta_{5} x_{3}+\beta_{6} x_{3}^{2}+\beta_{7} x_{1} x_{2}+\beta_{8} x_{1} x_{2}^{2} \\
& +\beta_{9} x_{1}^{2} x_{2}+\beta_{10} x_{1}^{2} x_{2}^{2}+\beta_{11} x_{1} x_{3}+\beta_{15} x_{2} x_{3}+\beta_{16} x_{2} x_{3}^{2}+\varepsilon
\end{aligned}
$$

\subsubsection{Analysis of the Effect of Interaction Between Aggregates}

Using equation (1) along with the coefficient values presented in Table 5, for conducting the two-way analysis along with the interaction, it was possible to evaluate the effect of the interaction between the \%FRA and the \%CRA, for concretes having different WC Ratio, as shown by the response surfaces in Figure 10, Figure 11 and Figure 12, respectively. 


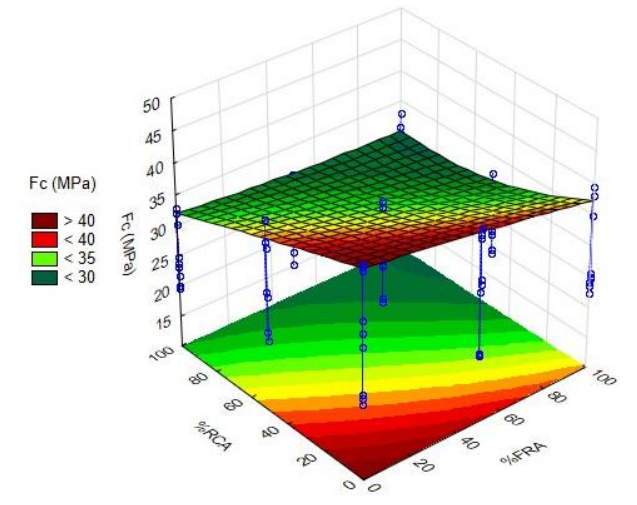

Figure 10 Effect of the interaction between the FRA and the CRA (WC Ratio $=0.50$ ).

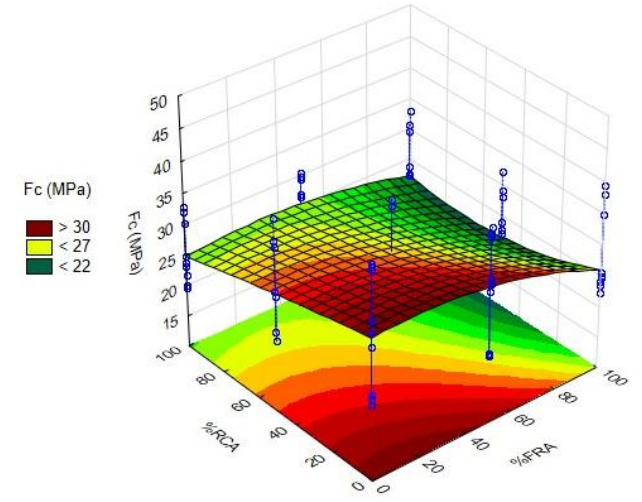

Figure 11 Effect of the interaction between the FRA and the CRA (WC Ratio $=0.65$ ).

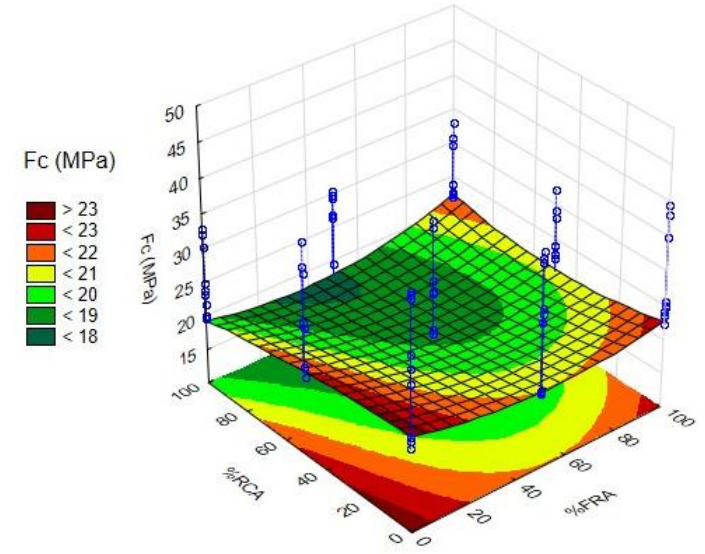

Figure 12 Effect of the interaction between the FRA and the CRA (WC Ratio $=0.80$ ).

From Figure 10, It can be seen that, for the concrete having a WC Ratio equal to 0.50 , the curve levels are found to be approximately parallel. This implies that there is a low interaction between the content of fine aggregates and coarse aggregates, indicating that the addition of aggregates with different particle sizes has a similar effect on the compressive strength.

In Figure 11, for concretes having a WC Ratio equal to 0.65 , the curve levels become curvilinear, indicating a greater effect of interaction between the \%CRA and the \%FRA on the overall compressive strength. The response surface also indicates that the increase in the coarse 
aggregate content possesses a greater impact on the reduction of the compressive strength compared to the increase in the content of fine aggregate. It was also verified that to obtain a determined value of the compressive strength; it was possible to use a larger amount of fine recycled aggregate rather than the coarse recycled aggregate.

For concretes having a WC Ratio of 0.80 , the effect of interaction between the fine aggregate and the coarse aggregate was found to be highly non-linear, as shown in Figure 12 . The identification of a point of minimization of compressive strength was seen for the content of coarse aggregate of $100 \%$ and fine aggregate content of $40 \%$.

The interaction of the evaluation presents relevant information for the mixed design of the concrete, allowing the design of concretes to have a target compressive strength and more content of recycled aggregate, which increases its sustainability.

\subsubsection{Analysis of the Effect of the Interaction Between Aggregate and Water-Cement Ratio}

The influence of the added recycled aggregates on the compressive strength is dependent on the content and type of aggregate inserted, including the WC Ratio. These factors are interrelated, affecting each other, and thus making it complicated to establish the compressive strength of concrete using traditional mixed design methods, which are primarily based on Abrams' Law. The establishment of new methods that could evaluate the interaction between these factors is, therefore, fundamental to guarantee a greater prediction of the mechanical properties of recycled concrete.

The relationship between the content of recycled aggregate and the water-cement ratio for all aggregates that are used are shown in Figure 13. The curve levels were obtained with Equation 1.
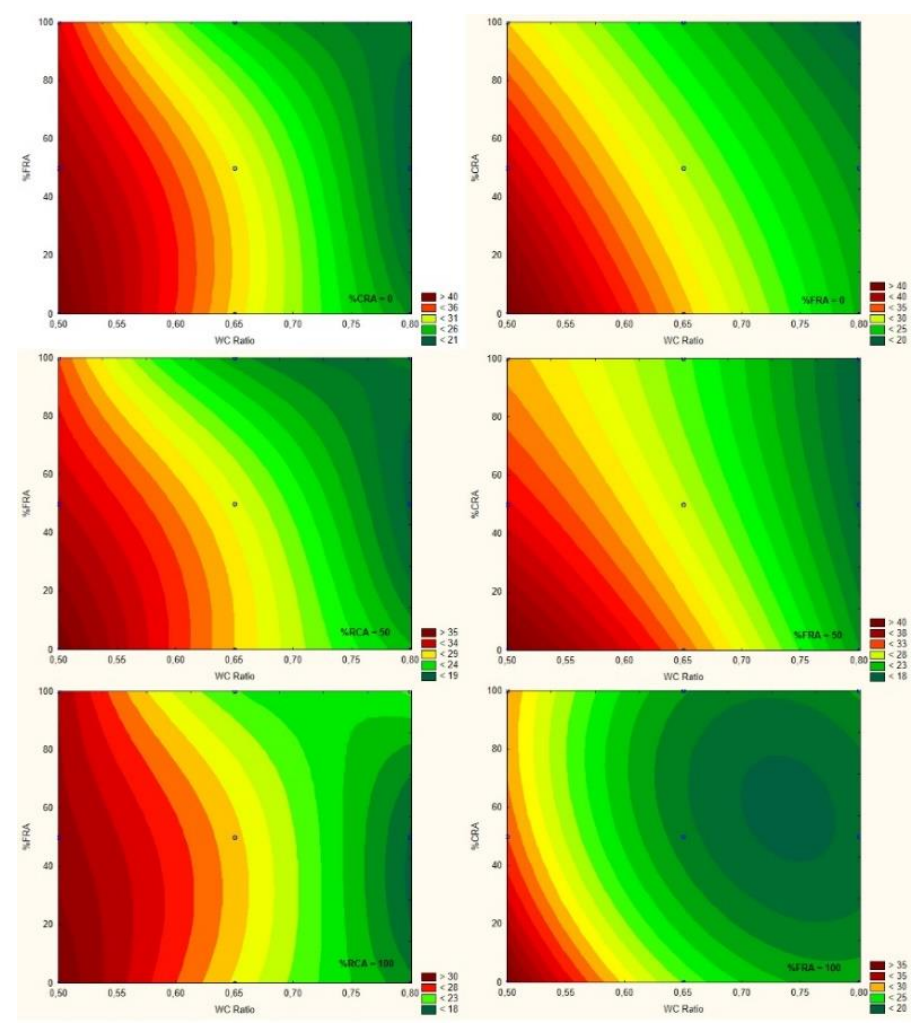

Figure 13 Influence of the interaction between WC Ratio and recycled aggregate content on compressive strength. 
The results confirm that the WC Ratio is the primary factor that defines the mechanical strength. However, it is possible to verify the influence of the type and content of recycled aggregate on the compressive strength of the concrete. Concrete with the same WC Ratio could have different compressive strengths depending on the type and content of aggregate. Limiting the situation during which $100 \%$ recycled aggregates are used in concrete that has a higher watercement ratio does not necessarily consist of the lowest compressive strength.

The interaction between the recycled aggregate and the water-cement ratio changes the behavior of the concrete in the fresh and hardened state. The increase in the water content in concrete mixtures modifies its workability and its ability to cast and mold in a fresh state. Due to the greater absorption capacity of the recycled aggregate, concretes that have higher contents of this aggregate could still present a lower water-cement ratio in the cement paste around the grain, which contributes to the increase in paste-aggregate adhesion strength and, consequently, the compressive strength of the concrete. In addition, this better adhesion modifies the concrete rupture mode, as previously discussed, making it possible for the rupture of the recycled aggregate, even for concretes with low compressive strength.

The curve levels shown in Figure 13 demonstrate that the statistical analysis provides an important mix design tool as it is possible to establish a combination of factors that provide the required compressive strength for the concrete. Compressive strength of approximately $30 \mathrm{MPa}$, for example, could be achieved using various combinations of water-cement ratio, fine aggregate content, and coarse aggregate content, respectively.

\section{Conclusions}

This work evaluates the effect on the compressive strength of concrete by the additional content of recycled aggregate, which was obtained from construction and demolition wastes. In addition, concretes with different water-cement ratios were also produced.

It was found that the compressive strength of concrete was affected by the fine recycled aggregate content, the coarse recycled aggregate content, and the water-cement ratio; in general, the concrete possessing a higher recycled aggregate content showed less compressive strength compared to conventional concrete. The reduction of the water/cement ratio is preponderant over the increase in the compressive strength due to its effect on the strength of the cement paste, but its interaction with the recycled aggregate indicates that, for concretes having $100 \%$ addition of recycled aggregate, the lower water content does not necessarily result in increased compressive strength.

From an experimental design consisting of 27 mixtures, a statistical model was obtained that had an interaction between the non-linear terms (two-way quadratic) that allowed the analysis of the interaction between the types of aggregates (fine or coarse) and the interaction between the aggregates and the water-cement ratio. The ANOVA results indicated that among the parameters evaluated, the water-cement ratio showed greater significance in determining the compressive strength of concrete, followed by the coarse recycled aggregate content and the fine recycled aggregate content.

The response surfaces and contour lines obtained with the statistical analysis allowed us to identify that the compressive strength is affected by the isolated action of the factors and the respective interaction that occurs between them. This determines the use of the mathematical 
model as an appropriate tool in the mixed design of recycled concrete. This is because the concrete mix design methods that are calibrated to produce conventional concrete fail to evaluate the effect of interaction between the parameters on the compressive strength of the recycled concrete.

\section{Acknowledgments}

The authors would like to thank the FAPESB, CAPES and CNPq.

\section{Author Contributions}

Monica Batista Leite: experimental analysis, investigation, formal analysis, supervision, project administration, review \& editing writing. Paulo Roberto Lopes Lima: experimental analysis, investigation; data curation, formal analysis; writing - original draft, review \& editing writing.

\section{Funding}

FAPESB (Fundação de Amparo a Pesquisa do Estado da Bahia).

\section{Competing Interests}

The authors have declared that no competing interests exist.

\section{References}

1. Luz AB, Almeida SL. Manual de agregados para construção civil. 2nd ed. Rio de Janeiro: CETEM/MCTI; 2012.

2. Oliveira FL, Mello EF. Sand mining and environmental impacts in the São João river basin, RJ. Revista Brasileira de Geociências. 2007; 37: 374-389. (In Portuguese)

3. Corinaldesi V, Moriconi G. Behaviour of cementitious mortars containing differents kinds of recycled aggregate. Constr Build Mater. 2009; 23: 289-294.

4. Rao A, Jha K, Misra S. Use of aggregates from recycled construction and demolition waste in concrete. Resour Conserv Recycl. 2007; 50: 71-81.

5. Paranavithana S, Mohajerane A. Effects of recycled concrete aggregates on properties of asphalt concrete. Resour Conserv Recycl. 2006; 48: 1-12.

6. Vegas I, Ibañez JA, San Jose JT, Urzelai A. Construction demolition wastes, Waelz salg and MSWI bottom ash: A comparative technical analysis as material for Road construction. Waste Manage. 2008; 28: 565-574.

7. Aragão HG, Aragão JJ, Lima PR, Lima JM, Leite MB. Análise teórica e experimental da deflexão de vigas $T$ pré-moldadas de concreto reciclado. Revista Sul-Americana de Engenharia Estrutural. 2019; 16: 114-134.

8. de Juan MS, Gutierrez MP. Influencia del árido reciclado en las propriedades del hormigón estructural. Las estructuras del siglo XXI, sostenibilidad, innovación y retos del futuro. 2005; 1: 413-425.

9. Lima PR, Leite MB. Influence of CDW recycled aggregate on drying shrinkage of mortar. Open J Civ Eng. 2012; 2: 53-57. 
10. Xiao JZ, Li JB, Zhang C. On relationships between the mechanical properties of recycled aggregate concrete: An overview. Mater Struct. 2006; 39: 655-664.

11. Leite MB. Evaluation of mechanical properties of concretes produced with recycled aggregates from construction and demolition waste. Porto Alegre: Federal University of Rio Grande do Sul; 2001.

12. Dantas AT, Leite MB, de Jesus Nagahama K. Prediction of compressive strength of concrete containing construction and demolition waste using artificial neural networks. Constr Build Mater. 2013; 38: 717-722.

13. Cabral AE, Schalch V, Dal Molin DC, Ribeiro JL. Mechanical properties modeling of recycled aggregate concrete. Constr Build Mater. 2010; 24: 421-430.

14. Jayasuriya A, Shibata ES, Chen T, Adams MP. Development and statistical database analysis of hardened concrete properties made with recycled concrete aggregates. Resour Conserv Recycl. 2021; 164: 105121.

15. Leite $M B$, do Filho JG, Lima PR. Workability study of concretes made with recycled mortar aggregate. Mater Struct. 2013; 46: 1765-1778.

16. ABNT - Brazilian Association of Technical Standards, 2007. NBR 5739: Concrete -Compression test of cylindric specimens - method of test. Rio de Janeiro, p. 9 (In Portuguese).

17. Xiao JZ, Li JB, Zhang C. Mechanical properties of recycled aggregate concrete under uniaxial loading. Cem Concr Res. 2005; 35: 1187-1194.

18. Duan ZH, Poon CS. Properties of recycled aggregate concrete made with recycled aggregates with different amounts of old adhered mortars. Mater Des. 2014; 58: 19-29.

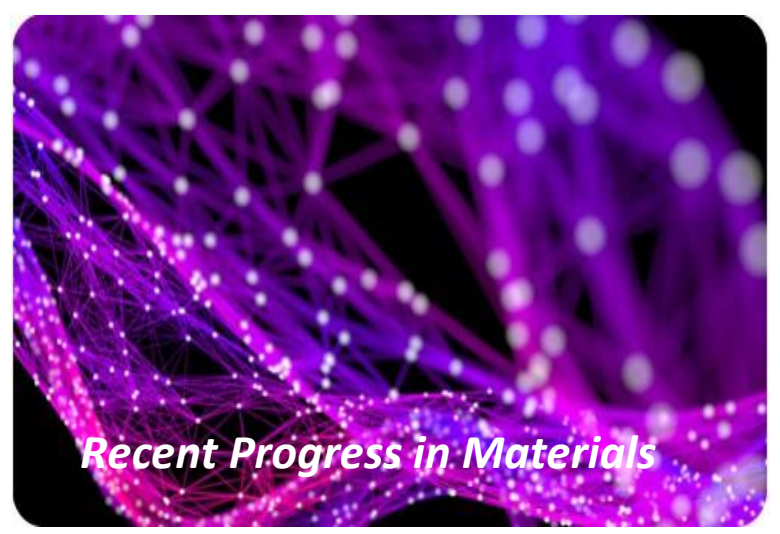

Enjoy Recent Progress in Materials by:

1. Submitting a manuscript

2. Joining in volunteer reviewer bank

3. Joining Editorial Board

4. Guest editing a special issue

For more details, please visit:

http://www.lidsen.com/journals/rpm 